\title{
Gastro-Intestinal Complaints Related to Various Eating Behaviors
}

\author{
Nathalie T. Burkert, Franziska Großschädl, Johanna Muckenhuber, Éva Rásky, \\ Willibald J. Stronegger and Wolfgang Freidl
}

Institute of Social Medicine and Epidemiology, Medical University Graz, Austria

\begin{abstract}
Background: Many studies report a beneficial health effect as well as a lower mortality rate for individuals following diets containing lots of fruits and vegetables. Results of studies on abdominal, and colon diseases are, however, inconsistent. Therefore, the aim of our study was to analyze differences between various eating behaviors and the incidence of gastro-intestinal complaints.
\end{abstract}

Methods: The sample used for this study was taken from the Austrian Health Interview Survey ATHIS 2006/07 $(\mathrm{N}=14$ 318). Logistic regressions were calculated controlling for age, BMI, and physical activity to analyze differences regarding the incidence of gastric or intestinal ulcer, abdominal pain, and specific medication taken due to these complaints.

Results: A lacto-/ovo-, as well as a semi-vegetarian diet is associated with a higher risk for gastrointestinal complaints. The odds ratio for gastric or intestinal ulcer, and the intake of specific medication is significantly higher for these diets.

Conclusion: A carnivorous diet containing also lots of fruits and vegetables is recommended to avoid abdominal complaints. Furthermore, public health programs are needed in order to reduce the health risk due to nutritional factors.

Keywords: Nutrition, diet, gastric or intestinal ulcer, abdominal pain, medication.

\section{INTRODUCTION}

Previous studies showed vegetarian diets to be associated with lower rates for hypertension, high cholesterol levels, specific chronic degenerative diseases, coronary artery disease, type II diabetes, gall stones, stroke, and certain cancers [1-7]. Overall, vegetarians have a lower body mass index $[1,4,5,7$ 11] a higher socioeconomic status [12], and a better health behavior, i.e. they are more physically active, drink less alcohol, and smoke less [8, 12, 13]. Therefore, a vegetarian diet is often recommended as a method to manage weight [9] and health [14]. On the other hand, vegetarians are more likely to consult alternative medical care and to take more medication [8].

However, evidence concerning lower rates of diseases of the colon is inconsistent $[5,7,15,16]$. Austin et al. [17] have found the odds ratio of getting a colorectal adenoma to be significantly higher in subjects who eat high amounts as well as in those consuming moderate amounts of meat. Many studies have shown that red meat consumption is associated with a higher risk for health, including diabetes, colon adenomas and colon cancer [18-22]. On the other hand, diets which allow small amounts of red meat, fish and dairy products seem to be associated with a reduced risk of coronary heart disease as well as type II diabetes [20]. Not only special nutrients are

*Address corresponding to this author at the Institute of Social Medicine and Epidemiology, Medical University Graz, Universitaetsstrasse 6/I, A-8010 Graz, Austria; Tel: 0043-316-380-7764; Fax: 0043-316-380-9665;

E-mail: nathalie.burkert@medunigraz.at associated with increased health risk, most of all caloric intake plays a crucial role $[19,23]$. Moreover, physical activity might be a stronger lifestyle factor for lowering disease rates, stronger than individual eating behavior $[15,24,25]$.

In conclusion, most studies have found a vegetarian diet to be associated with better health and lower mortality rates for certain diseases. Nevertheless, effects on gastrointestinal adenomas and colorectal cancer are inconsistent. Therefore, the aim of this study was to investigate the incidence of gastric or intestinal ulcer, abdominal pain for more than three months, and medication taken due to abdominal complaints, depending on various eating behaviors among Austrian adults.

\section{MATERIAL AND METHODS}

\section{Study Population}

The sample for this study was taken from the Austrian Health Interview Survey ATHIS 2006/07 [26]. The analyzed data were obtained from adults aged 20 years and older (14 318 participants; $55.1 \%$ female). The study was conducted through home-based personal interviews with interviewees representative for the Austrian population. The interviewees were chosen from the central population register and stratified by geographic region. The age distribution of the sample is shown in Table 1.

Overall, only $0.2 \%$ of the interviewees were vegan $(\mathrm{N}=22 ; 54.5 \%$ female $), \quad 0.8 \%$ were vegetarians 
Table 1: Age Distribution According to the Form of Nutrition

\begin{tabular}{|c|c|c|c|c|c|}
\hline \multirow{3}{*}{ Form of nutrition } & \multicolumn{5}{|c|}{ Age (years) } \\
\hline & $20-29$ & $30-39$ & $40-49$ & $50-59$ & $\geq 60$ \\
\hline & $\mathrm{N}=1955$ & $\mathrm{~N}=2421$ & $N=2958$ & $\mathrm{~N}=2359$ & $\mathrm{~N}=4625$ \\
\hline Vegans & $23.1 \%$ & $15.4 \%$ & $11.5 \%$ & $11.5 \%$ & $23.1 \%$ \\
\hline Lacto-/Ovo-Vegetarians & $21.9 \%$ & $19.5 \%$ & $16.4 \%$ & $7.8 \%$ & $11.7 \%$ \\
\hline Semi-Vegetarians & $23.3 \%$ & $18.0 \%$ & $18.5 \%$ & $10.6 \%$ & $18.5 \%$ \\
\hline $\begin{array}{c}\text { Meat diet combined with lots of fruit and } \\
\text { vegetables }\end{array}$ & $11.7 \%$ & $16.2 \%$ & $19.4 \%$ & $15.9 \%$ & $29.8 \%$ \\
\hline Meat diet with moderate meat intake & $10.3 \%$ & $14.0 \%$ & $18.3 \%$ & $15.4 \%$ & $36.4 \%$ \\
\hline Meat diet with heavy meat intake & $17.0 \%$ & $18.0 \%$ & $20.5 \%$ & $14.8 \%$ & $18.9 \%$ \\
\hline
\end{tabular}

Note. Data source: Austrian Health Interview Survey (ATHIS) 2006/07; n=14 318.

following an lacto-/ovo-diet ( $\mathrm{N}=99 ; 77.8 \%$ female), and $1.2 \%$ semi-vegetarians ( $\mathrm{N}=168 ; 76.2 \%$ female). $23.7 \%$ reported to eat a carnivorous diet with lots of fruit and vegetables ( $\mathrm{N}=3394 ; 67 \%$ female), $49.5 \%$ preferred a carnivorous diet with little meat $(\mathrm{N}=7 \quad 084 ; 60.6 \%$ female), and $24.8 \%$ a carnivorous diet with a lot of meat $(\mathrm{N}=3551 ; 31.1 \%$ female $)$.

\section{Measurements}

Face-to-face interviews conducted in private homes and long-term care facilities included questions regarding socio-demographic characteristics, diseases, health-related behavior, and psychological aspects.

The independent variable in this study was eating behavior. The participants were asked "How would you describe your eating behavior?". They described themselves as (1) vegan, (2) lacto-/ovo-vegetarians, (3) semi-vegetarians, (4) eating a carnivorous diet with lots of fruit and vegetables, (4) eating a carnivorous diet with little meat, or (6) eating a carnivorous diet with a lot of meat.

Dependent variables concerning gastro-intestinal complaints were: an incidence of gastric or intestinal ulcer, abdominal pain for more than three months, and medication taken due to these complaints.

\section{Statistical Analyses}

To analyze the differences and variation between individuals according to their eating behavior, in terms of gastro-intestinal complaints, Chi-square test, as well as logistic regression controlling for age, BMI, and physical exercise (total MET score) [27] was calculated for all variables. $P$-values $<0.05$ were considered as statistically significant. All analyses were calculated using IBM SPSS software (version 19.0) for Windows.

\section{RESULTS}

\section{Gastric or Intestinal Ulcer}

Overall, $7.1 \%$ (48\% women) of all study subjects suffer from a gastric or intestinal ulcer. While $13.6 \%$ $(\mathrm{N}=3 ; 33 \%$ female) of the vegans, $5.1 \%(\mathrm{~N}=5 ; 80 \%$ female) lacto-/ovo-vegetarians, and $4.2 \%(\mathrm{~N}=7 ; 86 \%$ female) of the semi-vegetarians suffer from gastric and intestinal ulcers, $5.8 \%(\mathrm{~N}=197 ; 63 \%$ women) of those eating a carnivorous diet with lots of fruits and vegetables, $6.9 \%$ ( $\mathrm{N}=244 ; 24 \%$ women) of those eating a carnivorous diet with heavy meat intake, and $7.8 \%$ $(\mathrm{N}=555 ; 52 \%$ women) of the moderate meat eaters suffer from ulcers $\left(x^{2}=19.03, p=.002\right)$. The results of logistic regression controlling for age, BMI, and physical exercise, showed that the odds ratio for the incidence of ulcers is 2.42 (Cl 1.01-5.78) for lacto-/ovovegetarians compared to those eating a carnivorous diet with heavy meat intake $(p=.047)$, and $2.42(\mathrm{Cl}$ 1.25-4.69) for semi-vegetarians $(p=.009)$.

Since a significant difference concerning the incidence of ulcer was found depending on the age of participants, the different age groups were analyzed separately. Only in the group of 20- to 29-year olds, and 50 to 59 year-old individuals the incidence of a gastric or intestinal ulcer is related to the eating behavior.

The 20 - to 29 -years-olds $17 \%$ of the vegans (1 woman), none of the lacto-/ovo-vegetarians and semivegetarians suffer from gastrointestinal ulcers, $2.1 \%$ $(\mathrm{N}=9 ; 78 \%$ women) of those eating a carnivorous diet with lots of fruits and vegetables, $2.1 \%(\mathrm{~N}=16 ; 56 \%$ women) of those eating a carnivorous diet with moderate meat intake, and $2.8 \%$ ( $\mathrm{N}=19 ; 26 \%$ women) of the heavy meat eaters have ulcers. The results of 
logistic regression analyzes showed that the odds ratio for the incidence of ulcer is $9.37(\mathrm{Cl} 1.02-86.02)$ for vegans compared to those eating a carnivorous diet with heavy meat intake $(p=.048)$.

In 50- to 59-year-olds none of the vegans and lactolovo-vegetarians, $10 \%$ (2 female) of the semivegetarians, $5 \%$ ( $N=31 ; 48 \%$ women) of those eating a carnivorous diet with lots of fruits and vegetables, $10 \%$ ( $\mathrm{N}=110 ; 57 \%$ women) of those eating a carnivorous diet with moderate meat intake, and 11\% ( $\mathrm{N}=63 ; 19 \%$ women) of the heavy meat eaters reported having gastric or intestinal ulcers. The results of logistic regression analyzes showed that the odds ratio for the incidence of ulcer is significantly reduced for subjects with a carnivorous diet with lots of fruits and vegetables (OR=0,48; $\mathrm{Cl} 0,30-0,75 ; p=.001$ ) compared to those eating a carnivorous diet with heavy meat intake.

\section{Abdominal Pain}

$1.2 \%(67.4 \%$ women) of all interviewees reported having abdominal pain for more than three months. None of the vegans, and lacto-/ovo-vegetarians, and $2.4 \% \quad(\mathrm{~N}=4 ; 75 \%$ female $)$ of the semi-vegetarians reported suffering from abdominal pain. $1 \%(\mathrm{~N}=35$; $77 \%$ women) of those combining a carnivorous diet with lots of fruits and vegetables, $1.2 \%(\mathrm{~N}=32 ; 41 \%$ women) of the heavy meat eaters, and $1.5 \%(\mathrm{~N}=107$; $72 \%$ women) of the moderate meat eaters reported abdominal pain for more than three months $\left(x^{2}=12.04\right.$, $\mathrm{p}=.034$ ). Results of the logistic regression analyzes revealed that the odds ratio of abdominal pain is 1.54 (Cl 1.03-2.31) for subjects with moderate meat intake, compared to heavy meat eaters $(p=.037)$.

\section{Gastro-Intestinal Medication}

Of all subjects, $3.8 \%$ (60\% women) reported that they have been taking gastro-intestinal medication within the past two weeks. While $3.3 \%(\mathrm{~N}=112 ; 65 \%$ women) of those combining a carnivorous diet with lots of fruits and vegetables, $2.8 \%(\mathrm{~N}=100 ; 34 \%$ women) of those eating a carnivorous diet with heavy meat intake, and $4.4 \%(\mathrm{~N}=315 ; 65 \%$ women $)$ of those who reported to eat meat moderately take medications against abdominal complaints. $4.5 \%$ (1 men) of the vegans, $6.1 \%(\mathrm{~N}=6$ women) of the lacto-/ovo-vegetarians, and $6.5 \%(\mathrm{~N}=11 ; 73 \%$ women) take specific medication $\left(x^{2}=24.67, p=.000\right)$. The odds ratio for medication is $2.42 \quad(\mathrm{Cl}$ 1.01-5.78) for lacto-/ovo-vegetarians compared to those combining a carnivorous diet with heavy meat intake $(p=.047)$, and $2.42(\mathrm{Cl} 1.25-4.69)$ for semi-vegetarians $(p=.000)$. All results are shown in Table 2 and $\mathbf{3}$.

\section{DISCUSSION}

Our results have shown that, overall, gastrointestinal complaints occur more often among lactolovo- and semi-vegetarians. Prior studies which analyzed the rates of abdominal diseases for different types of diets reported inconsistent results $[5,7,15$, 17]. Dwyer [5] found that a vegetarian diet is associated with a lower incidence of gallstones, better digestion, and less gastrointestinal diseases. Our study showed that after controlling for age, BMI, and physical activity, the risk of complaints, as well as medication is higher among vegetarians, but not for vegans. Since data bases on a cross-sectional study we cannot state directions of causal relationships. It is unclear whether a vegetarian diet causes gastrointestinal complaints, or if subjects become a vegetarian due to abdominal diseases. Since a vegetarian diet is often recommended as a method to manage weight [9] and health [14], our subjects might eat a vegetarian diet due to their disorders.

We also analyzed the association between the type of diet, and the prevalence of gastric or intestinal ulcer

Table 2: Prevalence of Abdominal Complaints Depending on the Form of Nutrition

\begin{tabular}{|c|c|c|c|c|}
\hline Form of nutrition & $\mathbf{N}$ & $\begin{array}{l}\text { Gastric or intestinal } \\
\text { ulcer }\end{array}$ & Abdominal pain & $\begin{array}{l}\text { Gastro-intestinal } \\
\text { medication }\end{array}$ \\
\hline Vegans & 22 & $13.6 \%(\mathrm{~N}=3)$ & $0 \%(\mathrm{~N}=0)$ & $4.5 \%(\mathrm{~N}=1)$ \\
\hline Semi-vegetarians & 168 & $4.2 \%(\mathrm{~N}=7)$ & $2.4 \%(\mathrm{~N}=4)$ & $6.5 \%(\mathrm{~N}=11)$ \\
\hline $\begin{array}{l}\text { Carnivorous diet combined with lots of fruit and } \\
\text { vegetables }\end{array}$ & 3394 & $5.8 \%(\mathrm{~N}=197)$ & $1.0 \%(\mathrm{~N}=35)$ & $3.3 \%(\mathrm{~N}=112)$ \\
\hline Carnivorous diet with high meat intake & 3551 & $6.9 \%(N=244)$ & $1.2 \%(\mathrm{~N}=32)$ & $2.8 \%(\mathrm{~N}=100)$ \\
\hline
\end{tabular}

Note. Data source: Austrian Health Interview Survey (ATHIS) 2006/07; n=14 318. 
Table 3: Odds Ratio and Confidence Interval for Abdominal Complaints Depending on the Form of Nutrition Controlled for Age, BMI and Physical Activity

\begin{tabular}{|c|c|c|c|c|c|c|}
\hline \multirow{2}{*}{$\begin{array}{c}\text { Form of nutrition } \\
\text { Carnivorous diet with high } \\
\text { meat intake compared to }\end{array}$} & \multicolumn{2}{|c|}{ Gastric or intestinal ulcer } & \multicolumn{2}{|c|}{ Abdominal pain } & \multicolumn{2}{|c|}{ Gastro-intestinal medication } \\
\hline & $\mathrm{OR}^{1}(95 \% \mathrm{CI})^{2}$ & $\mathbf{p}^{3}$ & $\mathrm{OR}^{1}(95 \% \mathrm{Cl})^{2}$ & $\mathbf{p}^{3}$ & $\mathrm{OR}^{1}(95 \% \mathrm{CI})^{2}$ & $\mathbf{p}^{3}$ \\
\hline Vegans & $1.48(0.19-11.50)$ & .707 & & & $1.48(0.19-11.50)$ & .707 \\
\hline Lacto/ovo-vegetarians & $2.42(1.01-5.78)$ & .047 & & & $2.42(1.01-5.78)$ & .047 \\
\hline Semi-vegetarians & $2.42(1.25-4.69)$ & .009 & $2.84(0.98-8.18)$ & .054 & $2.42(1.25-4.69)$ & .009 \\
\hline $\begin{array}{l}\text { Carnivorous diet combined with } \\
\text { lots of fruit and vegetables }\end{array}$ & $0.91(0.68-1.20)$ & .484 & $1.09(0.67-1.77)$ & .735 & $0.91(0.68-1.20)$ & .484 \\
\hline $\begin{array}{l}\text { Carnivorous diet with moderate } \\
\text { meat intake }\end{array}$ & $1.10(0.87-1.39)$ & .448 & $1.54(1.03-2.31)$ & .037 & $1.10(0.87-1.39)$ & .448 \\
\hline
\end{tabular}

Note. Data source: Austrian Health Interview Survey (ATHIS) 2006/07; $\mathrm{n}=14318 .{ }^{1} \mathrm{OR}=$ Odds Ratio; ${ }^{2} 95 \%-\mathrm{Cl}=95 \%$-Confidence Interval; ${ }^{3} \mathrm{p}=\mathrm{probability}$.

in different age groups. Interestingly, at younger ages a vegan diet is associated with a higher risk of gastric or intestinal ulcer, while in 50- to 59-year-olds those who eat a carnivorous diet with heavy meat intake have a higher risk compared to those who eat a diet rich in fruits and vegetables. This result is also reported by Austin [17] in a case control study which was conducted at the University of North Carolina. We could show that at all ages, a carnivorous diet rich in fruits and vegetables is associated with a beneficial health effect, and lower incidence of gastro-intestinal complaints.

Our results showed that the two vegetarian groups which have a higher risk of abdominal disorders also have a higher risk for taking medication due to gastrointestinal problems, which is congruent. Only abdominal pain for more than three months is related to a carnivorous diet with moderate meat intake. Since red meat intake is associated with an increased health risk [18-22], and also caloric intake plays a crucial role for health $[19,23]$, there is some likelihood that the interviewees in our study who reported eating meat on a sparse basis, eat a high proportion of red meat, and, therefore report more abdominal pain.

Strengths of the study include the large, representative sample of over 14000 individuals. The cross-sectional design of the study does not allow to state directions of causal relationships. Hence, further longitudinal studies are required to substantiate our results. Potential limitations of our results are that subjects identified themselves as being a vegetarian, or eating a carnivorous diet rich in fruits and vegetables, moderate or heavy meat intake. Additionally, information regarding caloric intake was not covered, and the vegan group was very small (22 subjects), while nearly $50 \%$ of Austrian adults $(60.8 \%$ female) eat a carnivorous diet with little meat. Therefore, in-depth research into the eating behavior of Austrian adults as well as studies analyzing gastro-intestinal complaints in relation to various eating behaviors is required.

To our knowledge, this is the first representative study which analyzes gastro-intestinal complaints related to nutrition in Austrian adults. Overall, studies report that lifestyle factors, such as physical activity, account for the disease rates stronger than the nutritional status $[15,24,25]$. Therefore our results are reinforced by the fact that we controlled for physical activity, age and BMI.

To sum up, our study shows that a vegetarian diet is associated with more gastro-intestinal complaints, while moderate meat intake combined with lots of fruits and vegetables seems to be beneficial for health. Our findings emphasize the necessity of taking nutritional factors into account as co-factors and possible contributors to abdominal complaints. We wish to highlight that a carnivorous diet combined with lots of fruits and vegetables is associated with a low prevalence of abdominal complaints. Therefore, this diet should be recommended, and public health programs are needed in order to reduce the health risk due to nutritional factors.

\section{CONFLICT OF INTEREST}

The authors declare no conflict of interest.

\section{REFERENCES}

[1] American Dietetic Association, Dietitians of Canada. Position of the American Dietetic Association and Dietitians of Canada: vegetarian diets. Can J Diet Pract Res 2003; 64(2): 62-81.

http://dx.doi.org/10.3148/64.2.2003.62 
[2] Craig WJ. Health effects of vegan diets. Am J Clin Nutr 2009; 89(5): 1627s-33s.

http://dx.doi.org/10.3945/ajcn.2009.26736N

[3] Craig WJ. Nutrition concerns and health effects of vegetarian diets. Nutr Clin Pract 2010; 25(6): 613-20.

http://dx.doi.org/10.1177/0884533610385707

[4] Craig WJ, Mangels AR, American Dietetic Association. Position of the American Dietetic Association: vegetarian diets.m J Am Diet Assoc 2009; 109(7): 1266-82. http://dx.doi.org/10.1016/j.jada.2009.05.027

[5] Dwyer JT, Health aspects of vegetarian diets. Am J Clin Nutr 1988; 48: 712-38.

[6] Key TJ, Appleby PN, Davey GK, Allen NE, Spencer EA, Travis RC. Mortality in British vegetarians: review and preliminary results from EPIC-Oxford. Am J Clin Nutr 2003; 78: 533s-58s. http://dx.doi.org/10.1079/PNS2005481

[7] Key TJ, Appleby PN, Rosell MS. Health effects of vegetarian and vegan diets. Proc Nutr Soc 2006; 65(1): 35-41.

[8] Baines S, Powers J, Brown WJ. How does the health and well-being of young Australian vegetarian women compare with non-vegetarians? Public Health Nutr 2007; 10(5): 43642.

http://dx.doi.org/10.1017/S1368980007217938

[9] Farmer B, Larson BT, Fulgoni VL, Rainville AJ, Liepa GU. A vegetarian dietary pattern as a nutrient-dense approach to weight management: an analysis of the national health and nutrition examination survey 1999-2004. J Am Diet Assoc 2011; 111(6): 819-27.

http://dx.doi.org/10.1016/j.jada.2011.03.012

[10] Rizzo NS, Sabaté J, Jaceldo-Siegl K, Fraser GE. Vegetarian dietary patterns are associated with a lower risk of metabolic syndrome: the adventist health study 2. Diabetes Care 2011; 34(5): 1225-27.

http://dx.doi.org/10.2337/dc10-1221

[11] Tonstad S, Butler T, Yan R, Fraser GE. Type of vegetarian diet, body weight, and prevalence of type 2 diabetes. Diabetes care 2009; 32(5): 791-96.

http://dx.doi.org/10.2337/dc08-1886

[12] Pollard J, Greenwood D, Kirk S, Cade J. Lifestyle factors affecting fruit and vegetable consumption in the UK women's cohort study. Appetite 2001; 37(1): 71-79. http://dx.doi.org/10.1006/appe.2001.0415

[13] Gacek M. Selected lifestyle and health condition indices of adults with varied models of eating. Rocz Pantsw Zakl Hig 2010; 61(1): 65-69.

[14] Leitzmann C. Vegetarian diets: what are the advantages? Forum Nutr 2005; 57: 147-56. http://dx.doi.org/10.1159/000083787

[15] Frentzel-Beyme R, Chang-Claude J. Vegetarian diets and colon cancer: the German experience. Am J Clin Nutr 1994; 59: $143 s-52 s$.
Fraser GE. Vegetarian diets: what do we know of their effects on common chronic diseases? Am J Clin Nutr 2009; 89: $1607 \mathrm{~s}-12 \mathrm{~s}$. http://dx.doi.org/10.3945/ajcn.2009.26736K

[17] Austin GL, Adair LS, Galanko JA, Martin CF, Satia JA, Sandler RS. A diet high in fruits and low in meat reduces the risk of colorectal adenomas. J Nutr 2007; 137(4): 999-1004.

[18] Flood A, Velie AM, Sinha R, et al. Meat, fat, and their subtypes as risk factors for colorectal cancer in a prospective cohort study in women. Am J Epidemiol 2003; 158: 59-68. http://dx.doi.org/10.1093/aje/kwg099

[19] Mathew A, Peters U, Chatterjee N, Kulldorff M, Sinha R. Fat, fiber, fruits, vegetables, and risk of colorectal adenomas. In J Cancer 2003; 158: 288-92.

[20] McEvoy CT, Temple N, Woodside JV. Vegetarian diets, lowmeat diets and health: a review. Public Health Nutr 2012; 3: $1-8$. http://dx.doi.org/10.1017/S1368980012000936

[21] Seow A, Quah SR, Nyam D, Straughan PT, Chua T, Aw TC. Food groups and the risk of colorectan carcinomas in an Asian population. Cancer 2002; 95: 2390-96. http://dx.doi.org/10.1002/cncr.10971

[22] Vang A, Singh PN, Lee JW, Haddad EH, Brinegar $\mathrm{CH}$. Meats, processed meats, obesity, weight gain and occurrence of diabetes among adults: findings from Adventist Health Studies. Ann Nutr Metab 2008; 52(2): 96-104. http://dx.doi.org/10.1159/000121365

[23] Boutron-Ruault MC, Senesse P, Meance S, Belghiti C, Faivre J. Energy intake, body mass index, physical activity, and the colorectal adenoma-carcinoma sequence. Nutr Cancer 2001; 39: $50-57$

http://dx.doi.org/10.1207/S15327914nc391 7

[24] Appleby PN, Key TJ, Thorogood M, Burr ML, Mann J. Mortality in British vegetarians. Public Health Nutr 2002; 5(1): 29-36. http://dx.doi.org/10.1079/PHN2001248

[25] Chang-Claude J, Hermann S, Eilber U, Steindorf K. Lifestyle determinants and mortality in German vegetarians and health-conscious persons: results of a 21-year follow-up. Cancer Epidemiol Biomarkers Prev 2005; 14(4): 963-68. http://dx.doi.org/10.1158/1055-9965.EPI-04-0696

[26] Klimont J, Kytir J, Leitner B. Oesterreichische Gesundheitsbefragung 2006/07. Hauptergebnisse und methodische Dokumentation. Wien: Statistik Austria 2007.

[27] Craig CL, Marshall A, Sjostrom M, et al. International Physical Activity Questionnaire: 12 country reliability and validity. Med Sci Sports Exer 2003; 35(8): 1381-95. http://dx.doi.org/10.1249/01.MSS.0000078924.61453.FB 